\title{
Gasdermin D deficiency attenuates arthritis induced by traumatic injury but not autoantibody-assembled immune complexes
}

Tong Yang 1,2 , Kai Sun ${ }^{1,2}$, Chun Wang ${ }^{2}$, Gaurav Swarnkar ${ }^{3}$, Songtao Quan ${ }^{4}$, Dustin Kress², Jianqiu Xiao², Yael Alippe ${ }^{2}$, Hongjun Zheng ${ }^{3}$, Robert H Brophy ${ }^{3}$, Dingjun Hao ${ }^{1}$, Audrey McAlinden ${ }^{3,5}$, Yousef Abu-Amer ${ }^{3,5}$, Jie Shen ${ }^{3}$ and Gabriel Mbalaviele $2^{*}$ (D)

\begin{abstract}
Background: Gasdermin D (GSDMD) is cleaved by several proteases including by caspase-1, a component of intracellular protein complexes called inflammasomes. Caspase-1 also converts pro-interleukin-1 $\beta$ (pro-IL-1 $\beta$ ) and pro-IL-18 into bioactive IL-1 $\beta$ and IL-18, respectively. GSDMD amino-terminal fragments form plasma membrane pores, which mediate the secretion of IL-1 $\beta$ and IL-18 and cause the inflammatory form of cell death pyroptosis. Here, we tested the hypothesis that GSDMD contributes to joint degeneration in the K/BxN serum transfer-induced arthritis (STIA) model in which autoantibodies against glucose-6-phosphate isomerase promote the formation of pathogenic immune complexes on the surface of myeloid cells, which highly express the inflammasomes. The unexpected outcomes with the STIA model prompted us to determine the role of GSDMD in the post-traumatic osteoarthritis (PTOA) model caused by meniscus ligamentous injury (MLI) based on the hypothesis that this pore-forming protein is activated by signals released from damaged joint tissues.
\end{abstract}

Methods: Gsdmd $d^{+/+}$and Gsdmd ${ }^{-/-}$mice were injected with K/BXN mouse serum or subjected to MLI to cause STIA or PTOA, respectively. Paw and ankle swelling and DXA scanning were used to assess the outcomes in the STIA model whereas histopathology and micro-computed tomography $(\mu \mathrm{CT})$ were utilized to monitor joints in the PTOA model. Murine and human joint tissues were also examined for GSDMD, IL-1 $\beta$, and IL-18 expression by qPCR, immunohistochemistry, or immunoblotting.

Results: GSDMD levels were higher in serum-inoculated paws compared to PBS-injected paws. Unexpectedly, ablation of GSDMD failed to reduce joint swelling and osteolysis, suggesting that GSDMD was dispensable for the pathogenesis of STIA. GSDMD levels were also higher in MLI compared to sham-operated joints. Importantly, ablation of GSDMD attenuated MLI-associated cartilage degradation ( $p=0.0097)$, synovitis $(p=0.014)$, subchondral bone sclerosis $(p=0.0006)$, and subchondral bone plate thickness $(p=0.0174)$ based on histopathological and $\mu C T$ analyses.

\footnotetext{
*Correspondence: gmbalaviele@wustl.edu

${ }^{2}$ Division of Bone and Mineral Diseases, Washington University School

of Medicine, 660 South Euclid Avenue, Campus Box 8301, St. Louis, MO 63110, USA

Full list of author information is available at the end of the article
} permits use, sharing, adaptation, distribution and reproduction in any medium or format, as long as you give appropriate credit to the original author(s) and the source, provide a link to the Creative Commons licence, and indicate if changes were made. The images or other third party material in this article are included in the article's Creative Commons licence, unless indicated otherwise in a credit line to the material. If material is not included in the article's Creative Commons licence and your intended use is not permitted by statutory regulation or exceeds the permitted use, you will need to obtain permission directly from the copyright holder. To view a copy of this licence, visit http://creativecommons.org/licenses/by/4.0/. The Creative Commons Public Domain Dedication waiver (http://creativeco mmons.org/publicdomain/zero/1.0/) applies to the data made available in this article, unless otherwise stated in a credit line to the data. 
Conclusion: GSDMD plays a key role in the pathogenesis of PTOA, but not STIA, suggesting that its actions in experimental arthropathy are tissue context-specific.

Keywords: GSDMD, IL-1, Inflammasome, Inflammation, Immune cells, Pyroptosis, Bone, Arthritis

\section{Background}

Compelling evidence implicates inflammation in the pathogenesis of rheumatoid arthritis (RA), an autoimmune disease characterized by synovial inflammation and joint damage [1]. Although the etiology of RA remains unclear, its progression is associated with dysregulated inflammatory actions of various cell types including macrophages, neutrophils, $\mathrm{T}$ cells, B cells, and synovial fibroblasts [2-6]. These responses take place within the synovium and lead to the formation of the pannus, a tumor-like structure, which ultimately invades and damages the cartilage and bone [7, 8]. Several inflammatory cytokines contribute to joint pathology in RA, but the most significant include TNF- $\alpha$, IL-1 $\beta$, and IL- 6 , some of which partner with RANKL to promote osteoclast differentiation and, ultimately, osteolysis [9-11]. This premise is supported by the proven clinical efficacy of drugs that neutralize the activity of these cytokines [12-17]. However, RA is a complex disease with superimposed actions of cytokines and autoantibodies, including rheumatoid factor, anti-citrullinated, and carbamylated protein autoantibodies [2-6]. As a result, certain patients are refractory to current cytokine-based therapies, and in spite of the pivotal role of IL-1 $\beta$ in maintaining synovitis and inducing bone erosion, IL-1 blockade shows limited efficacy in improving clinical symptoms of RA patients [15].

In contrast to RA, OA was historically deemed as a simple process of cartilage deterioration. However, the pathogenesis of OA is now viewed as a complex process, which depending on the etiology (e.g., caused by trauma) is attended by subchondral bone sclerosis, synovitis, osteophyte formation, and inflammation [18]. Dysregulated inflammatory networks include those governed by IL- 1 family members such as IL- $1 \alpha$, IL-18, and IL-1 $\beta[19,20]$, which are potent inducers of tissuedegrading enzymes such as matrix metalloproteases (MMPs) and a disintegrin and metalloproteinase with thrombospondin motifs (ADAMTS) [21, 22]. However, the role of IL-1 in OA remains inconclusive as both joint-protective and joint-damaging effects of IL-1 signaling blockage have been reported in various preclinical models $[23,24]$. More importantly, several clinical trials of OA have reported a limited efficacy of IL-1 biologics $[25,26]$. In the absence of efficacious diseasemodifying OA drugs, surgical approaches such as joint replacement are by far the most effective interventions to control pain and correct joint malformation of latestage OA patients. The high costs and invasive nature of these procedures justify the search for novel targets in the therapeutic intervention of OA.

Similar to IL-1 $\beta$ and IL-18, the gasdermin family member, GSDMD, is activated upon cleavage by caspase-1, a component of the inflammasomes, which are intracellular protein complexes that are assembled upon detection of pathogenic signals and sterile stressors [27]. GSDMD amino-terminal fragments oligomerize and form pores at the plasma membrane through which IL-1 $\beta$ and IL-18 are secreted as they lack the signal peptide for the transport through the conventional endoplasmic reticulum-Golgi pathway [28]. However, excessive GSDMD pore formation compromises the integrity of the plasma membrane and leads to lytic cell death pyroptosis [28]. Pyroptosis uncontrollably releases cell contents, which include not only the active form of IL-1 $\beta$ and IL-18 but also other highly inflammatory danger-associated molecular patterns (DAMPs) such as ATP, high mobility group box 1 (HMGB1), and S100A9 proteins [29]. The release of these DAMPs results in further recruitment of immune cells and the perpetuation of inflammation.

GSDMD is an attractive target for therapeutic intervention; this view stems from the demonstration that loss of this protein prevented the pathogenesis not only of autoinflammatory monogenic disorders such as neonatal-onset multisystem inflammatory disease (NOMID) and familial Mediterranean fever (FMF) in mice, but also complex diseases such as experimental autoimmune encephalitis (EAE) and sepsis [30-33]. Since GSDMD pores facilitate not only the secretion of IL-1 $\beta$, IL-18, and other small molecules by live cells (aka hyperactive cells) but also various inflammatory intracellular contents during pyroptosis, inhibition of GSDMD pore-forming activity could, in theory, provide superior efficacy over IL-1 blockade. However, this view is not universal as a recent paper reported that deletion of GSDMD had no impact on monosodium urate-induced gouty arthritis in mice [34]. A conflicting role of GSDMD in dextran sodium sulfate (DSS)-induced colitis in mice has also been reported $[35,36]$. Thus, the extent to which inhibition of GSDMD prevents the pathogenesis of complex diseases such as RA and OA has yet to be established.

In this study, we sought to determine the role of GSDMD in arthritis using mice sufficient or insufficient 
in this protein. We found that GSDMD deficiency attenuates arthropathy induced by traumatic injury but not immune complexes assembled by autoantibodies.

\section{Materials and methods Human tissues}

Synovial tissues were collected from eight late-stage OA patients ( 5 females, 3 males) with ages ranging from 56 to 74 years during total knee replacement (TKR) surgery and one healthy patient who had a bone fracture, during fixation removal surgery. The criteria for TKR included joint pain that lasted over 12 months with evidence of radiological changes including moderate joint space narrowing and osteophytes formation. OA cartilage was collected during total knee arthroplasty (TKA) from terminal OA patients whereas PTOA cartilage was obtained from patients who developed clinical signs of knee OA after anterior cruciate ligament (ACL) injury. Control cartilage was from areas with normal cartilage appearance from the same patients. The collection of tissues was approved by the review board of Washington University School of Medicine in St. Louis. All participants provided written informed consent.

\section{Mice}

Gsdmd knockout (Gsdmd ${ }^{-/-}$) mice, kindly provided by Dr. Vishva M. Dixit (Genentech, South San Francisco, CA), were generated using CRISPR-Cas9 technology [33]. All mice were backcrossed to the C57BL6 strain for at least 10 generations, and mouse genotyping was performed by PCR. All procedures were approved by the Institutional Animal Care and Use Committee (IACUC) of Washington University School of Medicine in St. Louis.

\section{Serum transfer-induced arthritis (STIA)}

Six-week-old Gsdmd $d^{+/+}$and $G s d m d^{-/-}$mice were injected with $\mathrm{K} / \mathrm{BxN}$ mouse serum $(150 \mu \mathrm{l})$ intraperitoneally on days 0 and 2 as described previously [37]. Mice inoculated with PBS served as controls. Mice were monitored daily after injections. Paw and ankle thicknesses were measured daily for 12 days with a digital caliper. Tissues were collected on day 12 for further analysis.

\section{Meniscal ligamentous injury (MLI) model}

Twelve-week-old Gsdmd ${ }^{+/+}$and Gsdmd ${ }^{-/-}$male mice were subjected to MLI surgery [38]. Briefly, the medial collateral ligament was transected, then a portion of the anterior medial meniscus was surgically removed without disrupting the patella and any other ligaments. Sham surgery was performed on the contralateral joint of the same mouse in which a similar incision is made on the medial side without the removal of the meniscus or the collateral ligament. Mice were sacrificed 12 weeks afterwards, and joint tissues were collected.

\section{Histology and immunochemistry}

The knee joints were fixed in $10 \%$ neutral buffered formalin at room temperature for $24 \mathrm{~h}$ then decalcified in Immunocal (StatLab, McKinney, TX) for 3 days; fresh Immunocal was changed every $24 \mathrm{~h}$. Tissues were processed and paraffin-embedded, then 5 - $\mu \mathrm{m}$-thick sagittal sections were generated, starting from the medial side of the knees. They were stained with Safranin-O. OARSI scoring was based on an established scoring system [39]. Synovitis scoring was based on the severity of synovium hyperplasia (score range $0-3$ ) and inflammatory cell infiltration (score range $0-3$ ) in the sub-synovial region [40]. All histological scoring was performed by two blinded reviewers.

For immunohistochemistry, the sections were deparaffinized and rehydrated using xylene followed by an ethanol gradient. Antigen retrieval was performed using citrate buffer (Dako, S1699) at 3 psi. The sections were incubated overnight at $4{ }^{\circ} \mathrm{C}$ with primary antibodies against GSDMD (1:200, Abcam, ab219800), followed by $1 \mathrm{~h}$ incubation with biotinylated goat secondary antibody (Vector Laboratories, BA-9200). DAB reagent (Vector Laboratories, SK-4100) was used for the peroxidase-substrate reaction.

\section{Micro-computed tomography}

Before decalcification, the knee joints were scanned at a resolution of $10 \mu \mathrm{m}, 55 \mathrm{kVp}, 145 \mu \mathrm{A}$, and $300 \mathrm{~ms}$ integration time, using a micro-computed tomography system ( $\mu$ CT 40 scanner; Scanco Medical AG, Zurich). Bone volume/total volume (BV/TV) and subchondral bone plate thickness of medial tibial subchondral bones were analyzed using the Scanco analysis software. 3D images were reconstructed using the Dragonfly software (Dragonfly 3.6, Object Research Systems (ORS) Inc., Montreal, Canada). A "PET" color scheme was used instead of the conventional black and white to highlight the subchondral bone changes.

\section{Scanning of the limbs}

The hindlimbs were scanned with Faxitron UltraFocus DXA (Hologic Inc., MA, USA). 3D images were reconstructed using Dragonfly software (Dragonfly 3.6, Object Research Systems (ORS) Inc., Montreal, Canada).

\section{Cell culture and treatment}

Murine primary bone marrow-derived macrophages (BMDMs) were obtained using the bone marrow from the femurs and tibiae in MEM- $\alpha$ (Gibco, 12561-049) with 10\% FBS (Gibco, 26140-079) and 1\% Pen/Strep (Gibco, 
15140-122) containing 10\% CMG, a source of M-CSF, for up to 5 days in a $150-\mathrm{mm}$ dish. After expansion, BMDMs were plated at a density of $5 \times 10^{4}, 1 \times 10^{6}$ cells/ well in a 16-well chamber slide, or $60 \mathrm{~mm}$ tissue culture dish, respectively. For inflammasome activation in vitro, BMDMs were primed with $100 \mathrm{ng} / \mathrm{ml}$ LPS (Sigma Aldrich, L4391) or $20 \mathrm{ng} / \mathrm{ml}$ TNF- $\alpha$ (R\&D systems, aa $80-235)$ for $3 \mathrm{~h}$, then followed with $15 \mu \mathrm{M}$ nigericin (Sigma Aldrich) for $1 \mathrm{~h}$.

Primary articular chondrocytes were isolated from murine femoral heads. Cells were harvested from the cartilage digested with collagenase $\mathrm{P}(0.5 \mathrm{mg} / \mathrm{ml}$, Roche, $11249002001)$ for $4 \mathrm{~h}$. Cells seeded at a density of $1 \times 10^{6}$ and $1 \times 10^{5}$ cells/well in 6 -well plate or 16 -well chamber slide, respectively, were treated with $1 \mathrm{ng} / \mathrm{ml} \mathrm{IL}-1 \beta$ for 24 h.

\section{qPCR}

Mice

RNA was isolated from whole paws 12 days after PBS or $\mathrm{K} / \mathrm{BxN}$ serum injection or femoral and tibia articular cartilage 4 weeks after sham or MLI surgery.

\section{Humans}

RNA was harvested from the articular cartilage from controls or patients with OA or PTOA. Total RNA was isolated using the PureLink RNA mini kit (Invitrogen). cDNA was synthesized using the iScript reverse transcription kit (Bio-Rad Laboratories) then amplified using Gsdmd/ GSDMD, Gsdme, IL1B, or IL18 primers (Supplementary Table 1). Gene expression was analyzed by qPCR using the SYBR green gene expression assay (Applied Biosystems).

\section{Western blot}

Cells and tissues were lysed with RIPA buffer $(50 \mathrm{mM}$ Tris, $150 \mathrm{mM} \mathrm{NaCl}, 1 \mathrm{mM}$ EDTA, 0.5\% NaDOAc, 0.1\% SDS, and 1.0\% NP-40) plus Complete Protease Inhibitor Cocktail and phosphatase inhibitors (Roche, South San Francisco, CA, USA). Protein concentrations from cell lysates and tissue lysates were determined by the Bio-Rad method. Proteins were separated by SDS-PAGE (12\%) and transferred to PVDF membranes, which were incubated with antibodies against mouse GSDMD (1:1000, ab219800, Abcam), human GSDMD (1:1000, ab210070, Abcam), or $\beta$-actin (1:5000, sc-47778, Santa Cruz Biotechnology, Dallas, TX, USA) overnight at $4{ }^{\circ} \mathrm{C}$, followed by a 1-h incubation with secondary goat anti-rabbit IgG (1:5000, A21109, Thermo Fisher Scientific, Waltham, MA, USA). The signals were developed using the Li-Cor Odyssey Infrared Imaging System (LI-COR Biosciences, Lincoln, NE, USA).
Measurements of IL-1 $\beta$ and lactate dehydrogenase (LDH) Cell death was assessed by the release of LDH in a conditioned medium using the LDH Cytotoxicity Detection Kit (TaKaRa, CA). IL-1 $\beta$ levels in conditioned media were measured by ELISA (eBiosciences, NY).

\section{Statistical analysis}

Statistical analysis was performed using repeated measures ANOVA and $t$ test analysis based on the data type (described in the figure legends) in GraphPad Prism (version 8.0.0, GraphPad Software, San Diego).

\section{Results}

GSDMD deficiency failed to reduce joint swelling and osteolysis in the STIA model

The serum of $\mathrm{K} / \mathrm{BxN}$ mice contains autoantibodies against glucose-6-phosphate isomerase (G6PI), which upon transfer to recipient animals consistently cause inflammatory arthritis [37]. This model commonly referred to as serum transfer-induced arthritis (STIA) reproduces the effector phase of RA as G6PI autoantibodies promote the formation of immune complexes that activate innate immune cells such as neutrophils and macrophages. The prominence of inflammasome pathways in myeloid cells, which play key roles in the pathogenesis of STIA, provided a strong rationale for determining the joint impact of GSDMD deficiency in this model. Inoculation of the arthritic serum but not PBS caused the swelling of the ankles (Fig. 1A; Fig. S1A) and paws (Fig. 1B) in Gsdmd ${ }^{+/+}$mice. These joint outcomes were unaffected in mice lacking GSDMD (Fig. 1A, B; Fig. $\mathrm{S} 1 \mathrm{~B})$. Likewise, bone destruction at the tibial-tarsal junctions was comparable between $G s d m d^{+/+}$and $G s d m d^{-/-}$ mice (Fig. 1C). These results suggest that GSDMD does not play a key role in the pathogenesis of STIA.

The unexpected comparable phenotype of $G s d m d^{+/+}$. and $G s d m d^{-/-}$-serum injected mice prompted us to analyze the expression of Gsdmd mRNA in the paws in this model. We found that paws from serum-treated WT mice expressed high levels of Gsdmd transcripts compared to PBS-treated controls (Fig. 1D). Levels of GSDME, another widely studied GSDM family member [41], were also higher in STIA paws compared to PBS counterparts (Fig. 1E). Thus, although GSDMD expression is induced by the antibodies-containing serum, its absence does not attenuate the associated inflammation and osteolysis.

\section{GSDMD expression was upregulated in PTOA joints}

Inhibition of inflammasomes, which are involved in the activation of GSDMD, prevents OA pathogenesis in various animal models [42-45]. Therefore, we determined the impact of GSDMD deficiency on the joints in the 


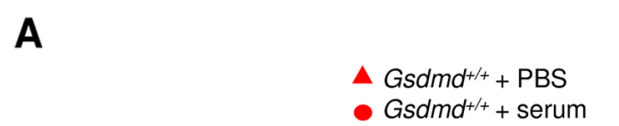

\section{B}

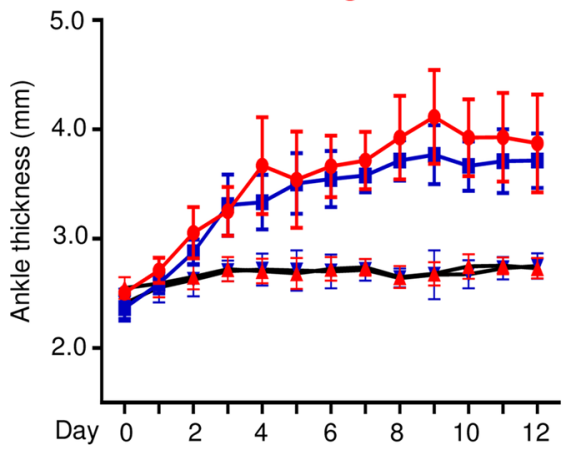

Gsdmd $\%+$ PBS

Gsdmd ${ }^{-\%}+$ serum

C

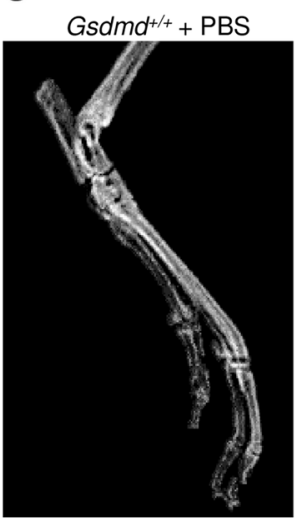

$G s d m d^{+/+}+$serum

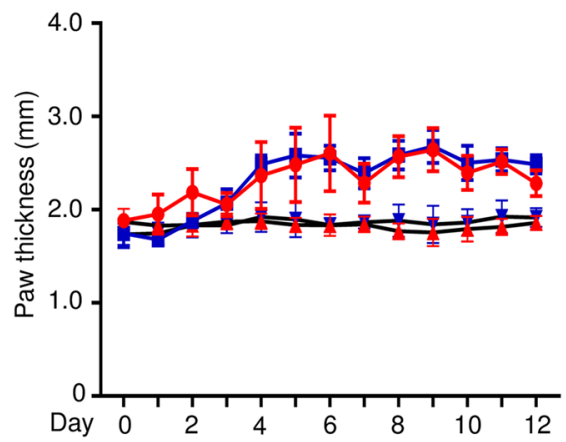

D
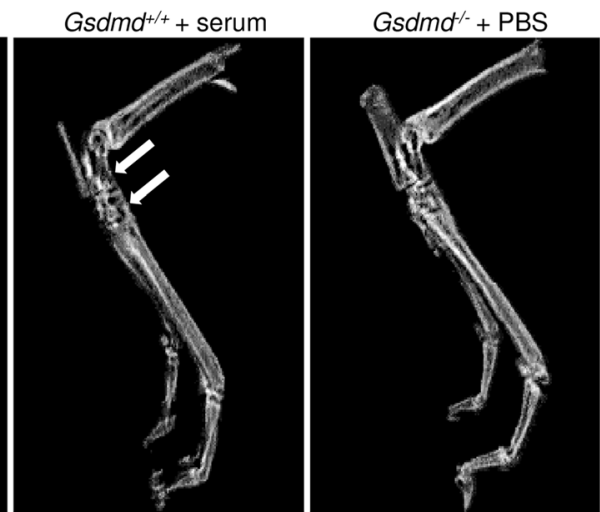

Gsdmd $d^{-1-}+$ serum

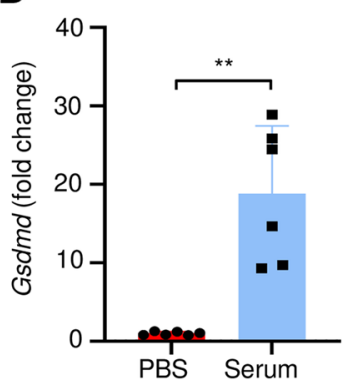

E

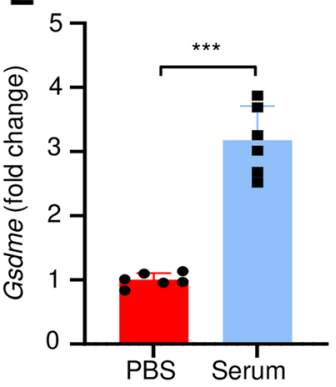

Fig. 1 GSDMD deficiency did not reduce joint swelling and osteolysis induced by STIA. Six-week-old mice were injected intraperitoneally with PBS

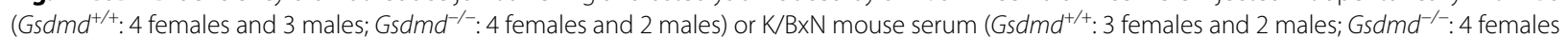
and 3 males) on days 0 and 2. Ankle (A) and paw (B) thicknesses were measured daily for 12 days with a digital caliper. No differences in joint swelling were noted between male and female mice. C The hindlimbs were collected on day 12 and scanned. White arrows indicate the areas of extensive osteolysis. D, E qPCR analysis of Gsdmd mRNA expression in Gsdmd $d^{+/+}$paw tissues. Data are mean \pm SD. Student's $t$ test; ${ }^{* *} p<0.01 ;{ }^{* * *} p<$ 0.001

PTOA model induced by meniscal ligamentous injury (MLI). First, we analyzed GSDMD expression in the articular cartilage. The articular cartilage from MLI mice expressed higher levels of Gsdmd mRNA compared to sham controls (Fig. 2A). We also analyzed the expression of GSDMD, IL1B, and IL18 mRNA in human articular cartilage. The levels of GSDMD (Fig. 2B) and $I L 1 B$ and
IL18 (Fig. 2C) transcripts were higher in human PTOA or OA articular cartilage compared to control counterparts. GSDMD expression was also increased in OA articular cartilage compared to control cartilage (Fig. S2A). Thus, GSDMD expression is upregulated in osteoarthritic articular cartilage. 
A

Mouse

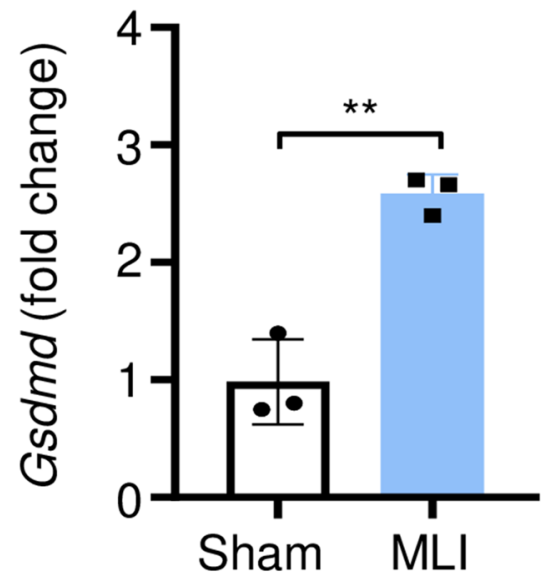

C

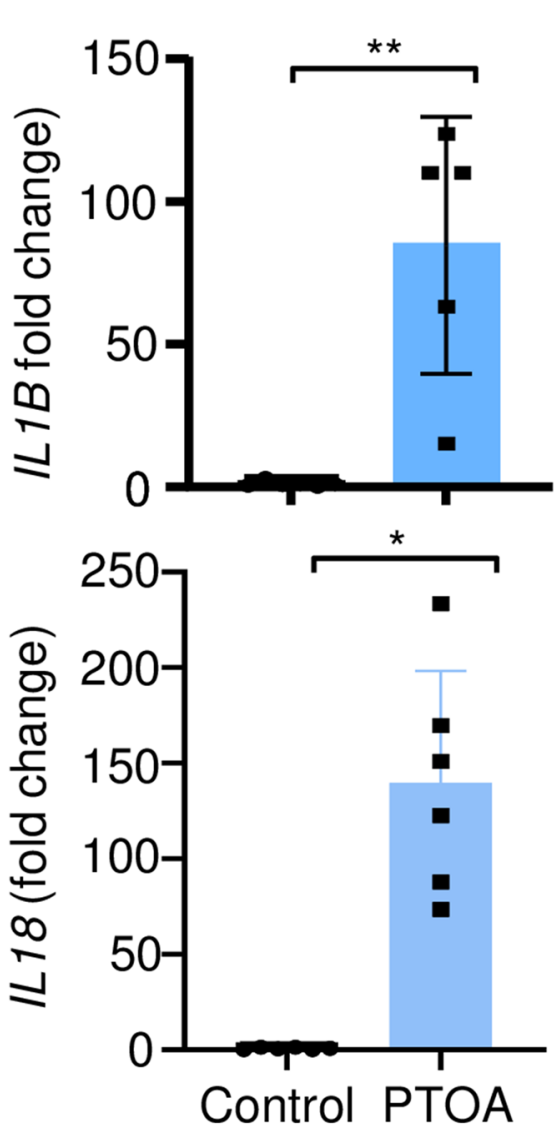

B

Human

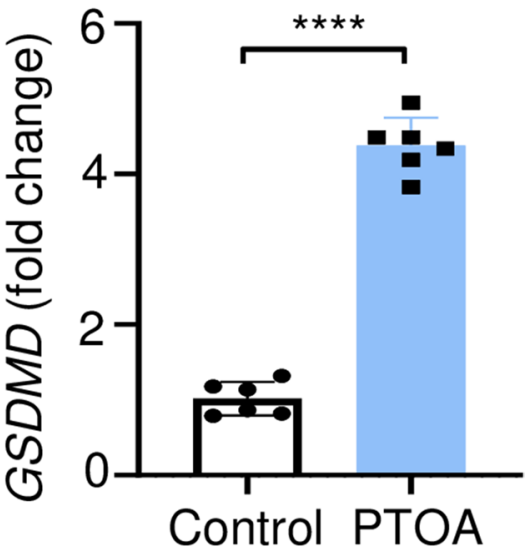

Human

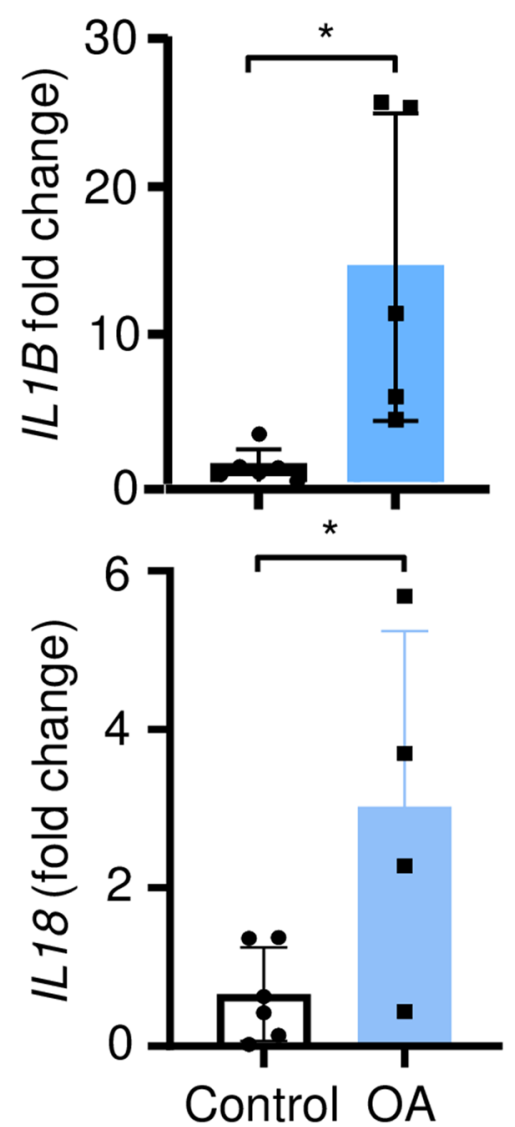

Fig. 2 Expression of GSDMD, IL-1 $\beta$, and IL-18 was increased in the articular cartilage from mice subjected to MLI and human PTOA patients. qPCR analysis of the gene expression in the articular cartilage from mice (sham surgery or MLI (A)) and human patients (control, OA, or PTOA (B, C)). The dot points reflect different patients or mouse samples. Data are mean \pm SD. Student's $t$ test; ${ }^{*} p<0.05 ;{ }^{* *} p<0.01 ;{ }^{* * * *} p<0.0001$ 
To further analyze GSDMD protein expression in the cartilage and surrounding tissues as well, specimens from the whole joint were immunostained with GSDMD antibodies. Immunohistochemical analysis showed that GSDMD was expressed in the bone marrow and synovium but was barely detected in the articular cartilage and meniscus in sham-operated knees (Fig. 3A-C). GSDMD expression persisted in the synovium and was induced in the meniscus and articular cartilage in the hind limbs subjected to MLI (Fig. 3D-F). The absence of the immunostaining in Gsdmd $d^{-/-}$tissues validated the specificity of the antibody (Fig. 3G-I). We also leveraged the immunoblotting method to determine the expression and activation state of GSDMD in the synovium of human patients. We found that GSDMD was cleaved in all synovium of OA patients that we analyzed (Fig. 3J). Collectively, the results show that GSDMD is expressed in several joint tissues including the cartilage, meniscus, and synovium.

Within the arthritic joints, cytokines such as TNF- $\alpha$ and IL-1 $\beta$ act on various cell types including macrophages $[19,46]$. For proof-of-concept studies, we determined the role of GSDMD in TNF- $\alpha$-induced production of IL-1 $\beta$ using macrophages from bone marrow instead

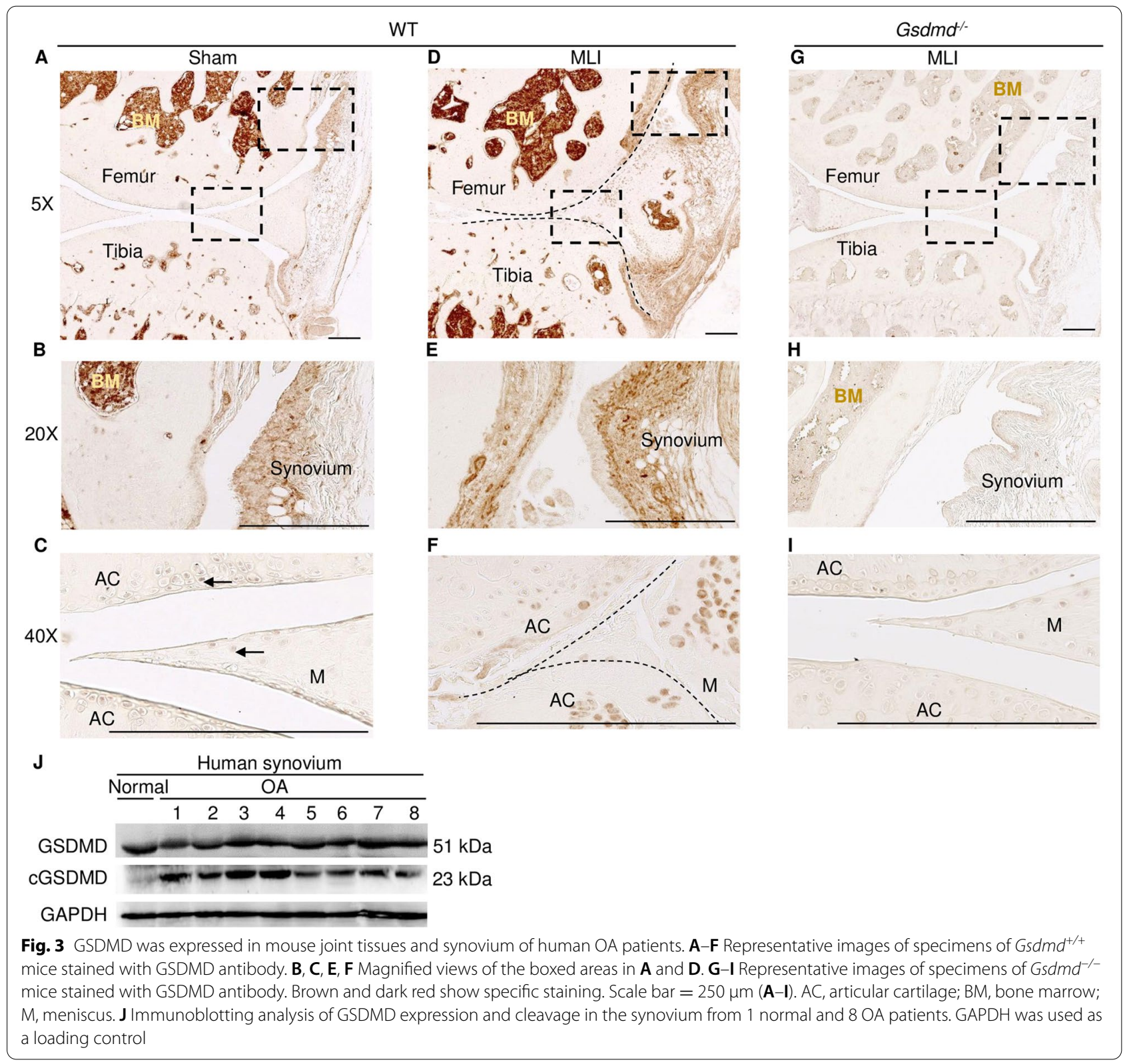


of arthritic tissues. Exposure of murine macrophages primed with TNF- $\alpha$ or LPS (positive control) to the ionophore nigericin, which induces NLRP3 inflammasome assembly [30] resulted in the cleavage of GSDMD (Fig. S2B), IL-1 $\beta$ secretion (Fig. S2C), and the release of lactate dehydrogenase (LDH), a readout of pyroptosis (Fig. S2D). These responses were all blunted in macrophages lacking GSDMD and are consistent with the known role of GSDMD in the propagation of inflammation.
GSDMD deficiency attenuated the loss of articular cartilage and synovitis in the murine PTOA model

To determine the impact of GSDMD deficiency on a joint response to injury, Gsdmd $d^{+/+}$and $G s d m d^{-/-}$ mice were subjected to MLI or sham surgery. Histological examinations of Safranin O-stained specimens revealed that articular cartilage and growth plates were morphologically comparable between sham-operated $\mathrm{Gsdm}^{+/+}$and $\mathrm{Gsdmd^{-/- }}$ knees (Fig. 4A), suggesting
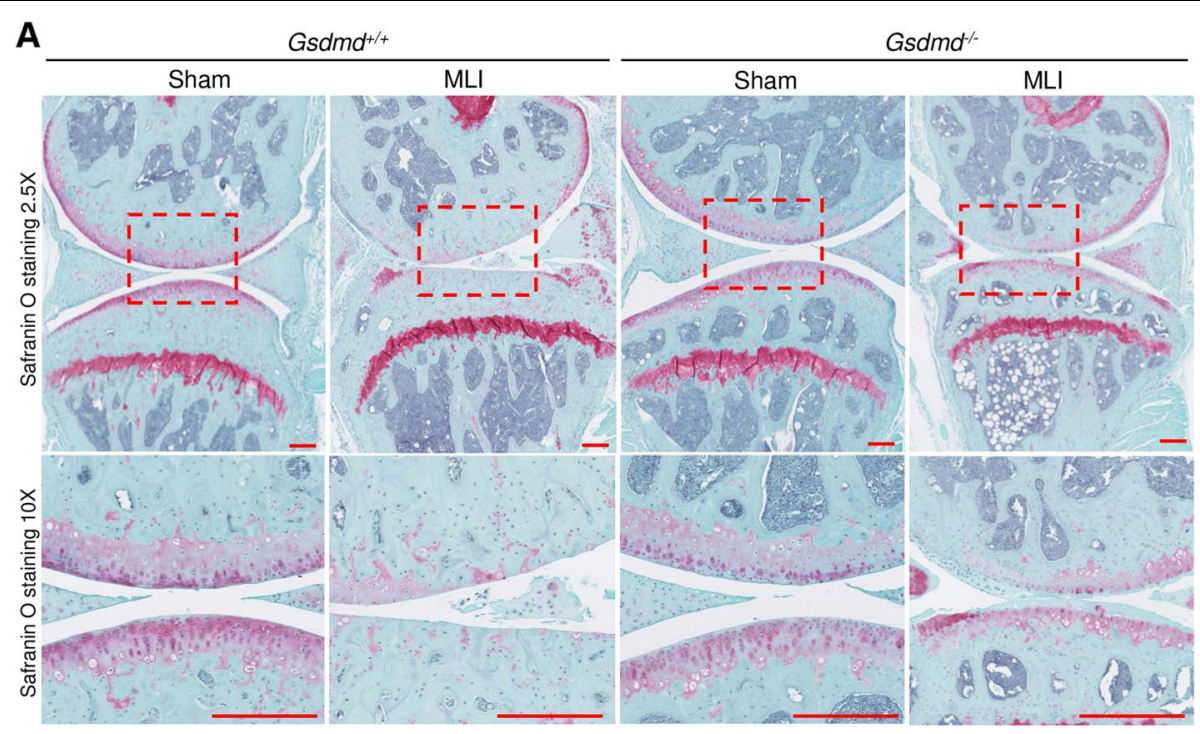

B
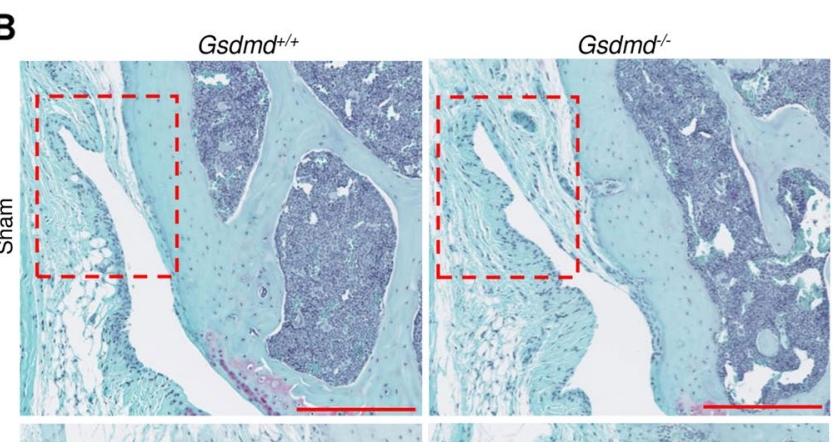

C $\quad-$ Gsdmdt/t
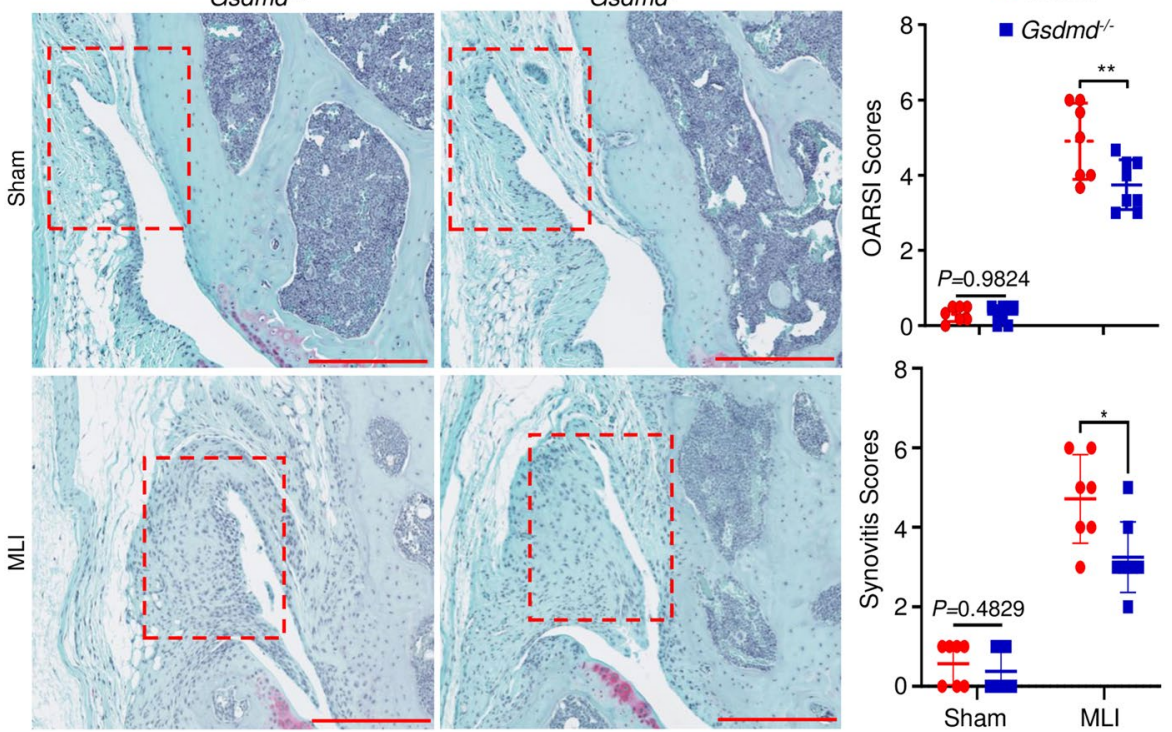

Fig. 4 GSDMD deficiency attenuated articular cartilage degeneration and synovitis. Twelve-week-old Gsdmd ${ }^{+/+}$and Gsdmd ${ }^{-/-}$male mice were subjected to sham or MLI surgery. A Representative images of Safranin-O staining of the left (sham) and right (MLI) knee joints. B Representative

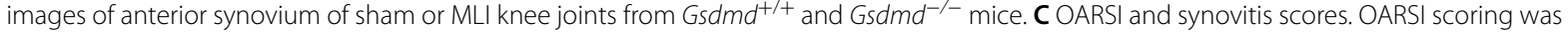
performed to quantify the severity of OA. Synovitis scores are based on the severity of synovial hyperplasia and sub-synovial inflammation. Reference data for $\mathbf{C}$ are shown in Fig. S3A. Data are mean \pm SD. N $=7-8 /$ group. Unpaired $t$ test; ${ }^{*} p<0.05 ;{ }^{* *} p<0.01$. Scale bar $=250 \mu m$ 
that this protein did not impact the development of these skeletal structures. MLI induced a marked loss of articular cartilage in $G s d m d^{+/+}$mice compared to $G s d m d^{-/-}$animals (Fig. 4A). This outcome was strongly correlated with OARSI scores, which were high in $G s d m d^{+/+}$compared to mutant mice (Fig. 4C and Fig. S3A). MLI also induced synovitis, which was more severe in $G s d m d^{+/+}$compared to $G s d m d^{-/-}$mice (Fig. 4B, C). Thus, GSDMD deficiency attenuates cartilage dedegeneration and synovitis in the PTOA model.

\section{GSDMD deficiency attenuated subchondral bone sclerosis in the murine PTOA model}

MLI perturbs various tissues in the joint, including subchondral bone [47]. To understand the role that GSDMD plays in subchondral bone sclerosis, we used $\mu \mathrm{CT}$ combined with a PET color scheme, instead of the conventional black and white modality, for visual examinations of bone changes. 3D reconstruction images showed that baseline bone morphology was comparable between

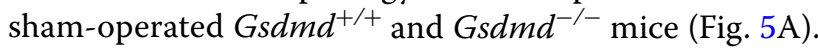
Focusing on the joint medial side, which is consistently affected in the MLI model [47], we found that the injury led to subchondral bone accrual in Gsdmd $d^{+/+}$ hind limbs, a response that was reduced in Gsdmd ${ }^{-/-}$ counterparts (Fig. 5A). Although subchondral BV/TV was slightly elevated in mutant compared to $G s d m d^{+/+}$ tibia (Fig. S3B), BV/TV and subchondral bone plate thickness changes between MLI and sham tibial plateaus were higher in $G s d m d^{+/+}$bones compared to
A
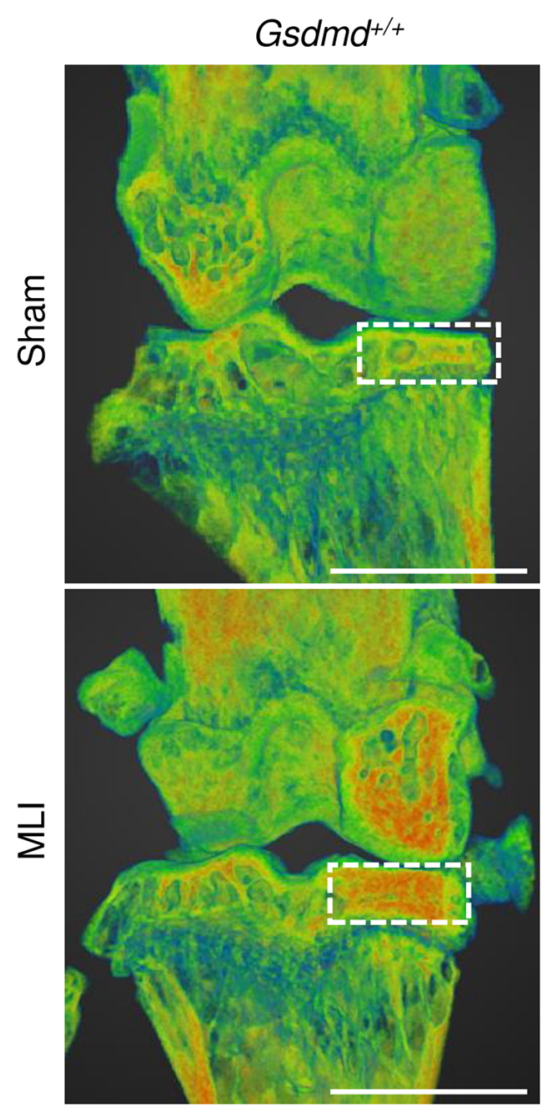

Low bone mass
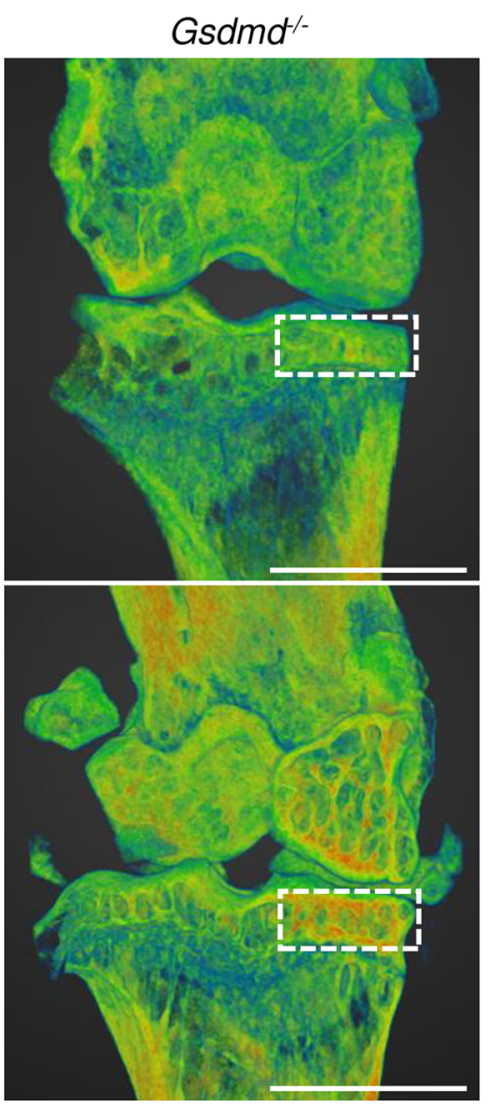

High bone mass

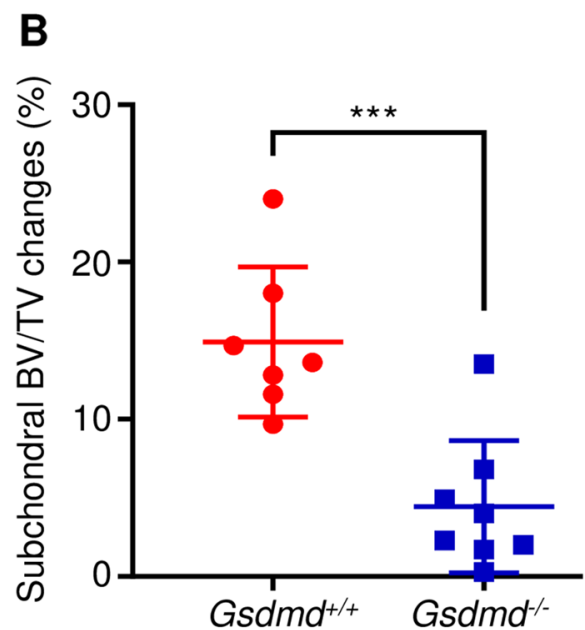

C

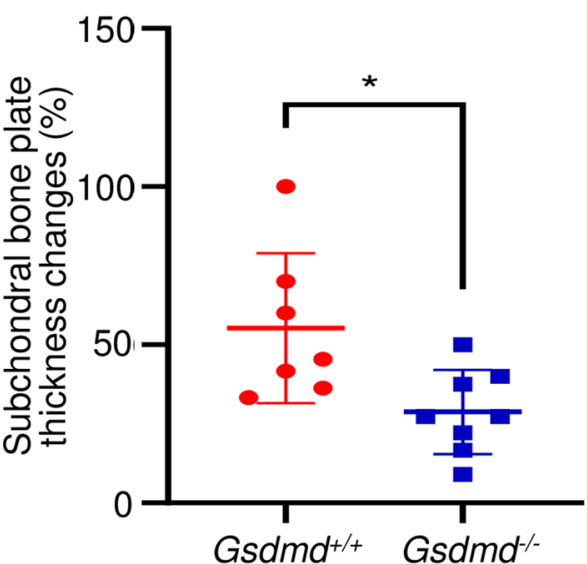

Fig. 5 GSDMD deficiency attenuated subchondral bone sclerosis. Twelve-week-old Gsdmd ${ }^{+/+}$and Gsdmd ${ }^{-/-}$male mice were subjected to sham or MLI surgery. A Representative three-dimensional $\mu \mathrm{CT}$ figures of sham and MLI knee joints. "PET" color scheme from the Dragonfly software was used to highlight the subchondral bone changes. B Subchondral BV/TV changes. MLI BV/TV/Sham BV/TV percentage for each mouse was used to quantify the extent of subchondral bone sclerosis. Reference data are shown in Fig. S3B. C Subchondral bone plate thickness changes. MLI thickness/sham thickness percentage for each mouse was used to quantify the extent of subchondral bone sclerosis. Data are mean \pm SD. $N=$ 7-8/group. Unpaired $t$ test; ${ }^{*} p<0.05$; $^{* *} p<0.001$. Scale bar $=5 \mathrm{~mm}$ 
Gsdmd $d^{-/}$counterparts (Fig. 5B, C). These results suggest that lack of GSDMD attenuates the pathogenesis of subchondral bone sclerosis in MLI-induced OA.

\section{Discussion}

We found that GSDMD was not essential for the pathogenesis of STIA. This finding from a model in which the effector phase of arthritis was driven by myeloid cells was unexpected because these cells express high levels of GSDMD [41]. In addition, loss of GSDMD was shown to prevent tissues from damage in disease models of EAE, NOMID, IBD, sepsis, and FMF [30-33]. We postulate that the unanticipated outcome of GSDMD deficiency in the STIA model may be the result of redundancy among GSDM family members. GSDME was the likely culprit because of its ability to complement GSDMD functions [41, 48-50], and, like GSDMD, its levels were higher in STIA paws compared to PBS paws. Non-essential or conflicting roles for several proteins that operate upstream or downstream of GSDMD had also been reported in models of inflammatory arthritis. Indeed, mice lacking the inflammasome adaptor protein apoptosis-associated speck-like protein containing a CARD (Asc) but not Nlrp3 or caspase-1 mice were protected from collageninduced arthritis and antigen-induced arthritis $[51,52]$ whereas NLRP3 and IL-1 receptor type 1 (IL-1R1) were important for the pathogenesis of arthritis induced by A20 ablation [53]. Furthermore, the lack of IL-1 signaling in mice suppressed CIA-driven arthritis [54]. Thus, not only GSDMD, but also several components of its signaling pathway are dispensable in animal models of autoimmune arthritis.

The development of PTOA caused by MLI is associated with increased levels of pro-inflammatory cytokines such as IL- $1 \beta$ and TNF- $\alpha$, whose downstream targets include matrix-degrading enzymes such as MMPs and aggrecanases [21, 22]. Consistent with the pro-inflammatory actions of GSDMD, MLI-induced OA is significantly attenuated in mice lacking this pore-forming protein. Thus, besides NOMID, FMF, EAE, and sepsis, PTOA is another experimental disease model in which ablation of GSDMD attenuates tissue damage [30-33]. These genetic proof-of-concept studies provide a rationale for testing the efficacy of GSDMD inhibitors such as FDA-approved disulfiram and dimethyl fumarate in $\mathrm{OA}$ pathogenesis $[55,56]$. Although blocking specific components of the inflammasome pathways such as IL- $1 \beta$ provides limited efficacy in OA, the expectation is that by preventing the release of not only IL- $1 \beta$ and IL-18 but also pyroptosis, inhibition of GSDMD may provide superior efficacy over IL-1 blockade [30].

GSDMD deficiency attenuated not only cartilage deterioration but also subchondral bone sclerosis, consistent with the bone-cartilage interplay during the pathogenesis of OA [57]. Subchondral bone sclerosis correlates with decreased bone remodeling and is believed to promote the initiation and progression of OA as it creates a stiff structure that promotes cartilage degeneration [57]. This dogma is consistent with our results though baseline subchondral bone mass is higher in GSDMD-deficient mice compared to WT littermates. Mechanistically, we recently reported that metaphyseal trabecular bone mass is increased in GSDMD-deficient mice as the result of decreased osteoclast differentiation [58]. However, efforts to understand whether bony changes precede cartilage alterations or vice versa are constrained by the uneasy access to floxed-Gsdmd mice for tissue-specific ablation of GSDMD.

GSDMD was expressed in the synovium. Although the characterization of GSDMD ${ }^{+}$cells in the synovium was outside the scope of this study, we posited that they included macrophages, which populate this tissue in various arthritis disease models $[19,46,59]$ and highly express GSDMD [30, 41, 58]. Within the synovium, GSDMD activation by cleavage is likely induced by cytokines and inflammasome assembly molecules such ATP and debris from dying cells or damaged tissues $[60,61]$. We found that GSDMD was cleaved in the samples from OA patients. However, the limitation of this observation was the challenge of obtaining several healthy synovial tissues for rigorous comparison of the extent of GSDMD cleavage between normal and OA samples. Despite this shortcoming, we contend that the actions of GSDMD in the synovium and other tissues such as the meniscus may culminate in cartilage deterioration in PTOA. Cartilage catabolic actions of GSDMD may also be chondrocyte autonomous as these cells express this protein. The ability of chondrocytes to upregulate GSDMD expression upon exposure to IL-1 $\beta$ (Fig. S4) suggests autocrine events whereby this cytokine acts locally on these cells to perpetuate cartilage demise.

\section{Conclusions}

In conclusion, GSDMD was induced in the cartilage and synovium of OA patients and mouse model of this disease. Importantly, GSDMD deficiency attenuated cartilage degeneration, synovitis, and subchondral bone sclerosis in the murine PTOA model, findings that provide a rationale for translational studies in OA using FDA-approved drugs that interfere with GSDMD poreforming activity. 


\section{Abbreviations}

GSDMD: Gasdermin D; GSDME: Gasdermin E; IL-1: Interleukin-1; LDH: Lactate dehydrogenase; MLI: Meniscus ligamentous injury; OA: Osteoarthritis; PTOA: Post-traumatic osteoarthritis; RA: Rheumatoid arthritis; RANKL: Receptor activator of NF-KB ligand; STIA: Serum transfer-induced arthritis.

\section{Supplementary Information}

The online version contains supplementary material available at https://doi. org/10.1186/s13075-021-02668-8.

Additional file 1: Figure S1. GSDMD deficiency did not reduce joint swelling and osteolysis induced by STIA. Six-week-old mice were injected intraperitoneally with PBS (Gsdmd ${ }^{+/+}: 4$ females and 3 males; Gsdmd ${ }^{-/-}: 4$ females and 2 males) or K/BxN mouse serum (Gsdmd ${ }^{+/+}: 3$ females and 2 males; Gsdmd ${ }^{-1-}: 4$ females and 3 males) on day 0 and 2. (A and B) Ankle thickness was measured daily for 12 days with a digital caliper. No differences in joint swelling were noted between male and female mice.

Additional file 2: Figure S2. GSDMD expression in articular cartilage of $O A$ patients, cleavage and mediation of $I L-1 \beta$ and $L D H$ release in murine macrophages. (A) qPCR analysis of GSDMD expression in articular cartilage of OA patients. Immunoblotting analysis of GSDMD cleavage (B) and IL-1 $\beta$ and $\mathrm{LDH}$ release in murine macrophages $(\mathbf{C}, \mathbf{D})$. Gsdmd ${ }^{+/+}$and $\mathrm{Gsdm}^{-1}$ macrophages were primed with $100 \mathrm{ng} / \mathrm{ml}$ LPS or $30 \mathrm{ng} / \mathrm{ml} \mathrm{TNF-a} \mathrm{for}$ $3 \mathrm{~h}$ and treated with $15 \mu \mathrm{M}$ nigericin for 1 hour. Whole-cell lysates were analyzed by immunoblot assay. IL-1 $\beta$ and LDH levels were measured in conditioned media. Data are representative of at least 3 independent experiments run in technical replicates and are mean \pm SD. ${ }^{* * *}, p<0.001$; ****, $p<0.0001$.

Additional file 3: Figure S3. Cartilage degeneration and subchondral bone sclerosis in MLI mice. Twelve-week-old Gsdmd ${ }^{+/+}$and Gsdmd ${ }^{-1-}$ male mice were subjected to sham or MLI surgery. (A) OARSI scoring was performed to quantify the severity of OA. Two-way repeated measurement ANOVA analysis was used to determine the interaction effect. (B) Subchondral bone BV/TV was measured by $\mu \mathrm{CT}$ to quantify the extent of subchondral bone sclerosis. Two-way repeated measurement ANOVA analysis was used to determine the interaction effect. $N=7-8 /$ group. Data are mean $\pm S D$. ${ }^{* *}, p<0.01 ;{ }^{* * *}, p<0.001$

Additional file 4: Figure S4. Effects of IL-1 $\beta$ on GSDMD expression in articular cartilage chondrocytes. Primary articular chondrocytes were treated with $1 \mathrm{ng} / \mathrm{ml} \mathrm{IL-1 \beta}$ for 24 hours. Whole-cell lysates were used for immunoblotting analyze GSDMD expression. $\beta$-actin was used as a loading control.

\section{Additional file 5 .}

\section{Acknowledgements}

Not applicable.

\section{Authors' contributions}

All authors were involved in drafting the article or revising it critically for important intellectual content, and all authors approved the final version to be published. GM has full access to all of the data in the study and takes responsibility for the integrity of the data. Study conception and design: GM,TY, JS, YA-A, and AM. Acquisition of data:TY, KS, CW, GS, SQ, DK, JX, YA, DH, and $\mathrm{HZ}$. Contribution of human joint tissues: RHB. Analysis and interpretation of the data:TY, JS, and GM

\section{Funding}

This work was supported by NIH/NIAMS AR068972 and AR076758 grants to GM. JS was supported by NIH grants AR075860, AR077616, and AR077226. YA-A by NIH grants AR049192, AR074992, and AR072623 and by grant \#85160 from the Shriners Hospital for Children. A.M. was supported by NIH grants AR077203 and AR075730.

\section{Availability of data and materials}

All data generated or analyzed during this study are included in this published article [and its supplementary information files].

\section{Declarations}

Ethics approval and consent to participate

The collection of synovial tissues and articular cartilage from OA patients was approved by the review board of Washington University School of Medicine in St. Louis.

All procedures were approved by the Institutional Animal Care and Use Committee (IACUC) of Washington University School of Medicine in St. Louis.

\section{Consent for publication}

Not applicable.

\section{Competing interests}

Dr. Gabriel Mbalaviele is a consultant for Aclaris Therapeutics, Inc. All other authors declare that they have no competing interests.

\section{Author details}

${ }^{1}$ Xi'an Jiaotong University Health Science Center, Xi'an, Shaanxi, China.

${ }^{2}$ Division of Bone and Mineral Diseases, Washington University School of Medicine, 660 South Euclid Avenue, Campus Box 8301, St. Louis, MO 63110, USA. ${ }^{3}$ Department of Orthopaedic Surgery, Washington University School of Medicine, St. Louis, MO, USA. ${ }^{4}$ Luoyang Orthopedic - Traumatological Hospital of Henan Province, Luoyang, Henan, China. ${ }^{5}$ Shriners Hospital for Children, St. Louis, MO, USA.

Received: 13 July 2021 Accepted: 31 October 2021

Published online: 16 November 2021

\section{References}

1. Nygaard G, Firestein GS. Restoring synovial homeostasis in rheumatoid arthritis by targeting fibroblast-like synoviocytes. Nat Rev Rheumatol. 2020;16(6):316-33.

2. O'Neil LJ, Barrera-Vargas A, Sandoval-Heglund D, Merayo-Chalico J, Aguirre-Aguilar E, Aponte AM, et al. Neutrophil-mediated carbamylation promotes articular damage in rheumatoid arthritis. Sci Adv. 2020;6(44):eabd2688.

3. Harre U, Georgess D, Bang H, Bozec A, Axmann R, Ossipova E, et al. Induction of osteoclastogenesis and bone loss by human autoantibodies against citrullinated vimentin. J Clin Invest. 2012;122(5):1791-802.

4. Kleyer A, Finzel S, Rech J, Manger B, Krieter M, Faustini F, et al. Bone loss before the clinical onset of rheumatoid arthritis in subjects with anticitrullinated protein antibodies. Ann Rheum Dis. 2014;73(5):854-60.

5. Negishi-Koga T, Gober HJ, Sumiya E, Komatsu N, Okamoto K, Sawa S, et al. Immune complexes regulate bone metabolism through FcRy signalling. Nat Commun. 2015;6:6637.

6. Hecht C, Englbrecht M, Rech J, Schmidt S, Araujo E, Engelke K, et al. Additive effect of anti-citrullinated protein antibodies and rheumatoid factor on bone erosions in patients with RA. Ann Rheum Dis. 2015;74(12):2151-6.

7. Buckley CD, Ospelt C, Gay S, Midwood KS. Location, location, location: how the tissue microenvironment affects inflammation in RA. Nat Rev Rheumatol. 2021;17(4):195-212.

8. Schett G, Gravallese E. Bone erosion in rheumatoid arthritis: mechanisms, diagnosis and treatment. Nat Rev Rheumatol. 2012;8(11):656-64.

9. Tian J, Chen JW, Gao JS, Li L, Xie X. Resveratrol inhibits TNF-alpha-induced IL-1 beta, MMP-3 production in human rheumatoid arthritis fibroblast-like synoviocytes via modulation of PI3kinase/Akt pathway. Rheumatol Int. 2013;33(7):1829-35

10. Lam J, Takeshita S, Barker JE, Kanagawa O, Ross FP, Teitelbaum SL. TNF-alpha induces osteoclastogenesis by direct stimulation of macrophages exposed to permissive levels of RANK ligand. J Clin Invest. 2000;106(12):1481-8.

11. Zhang YH, Heulsmann A, Tondravi MM, Mukherjee A, Abu-Amer Y. Tumor necrosis factor-alpha (TNF) stimulates RANKL-induced osteoclastogenesis via coupling of TNF type 1 receptor and RANK signaling pathways. J Biol Chem. 2001:276(1):563-8.

12. Bechtold S, Simon D. Growth abnormalities in children and adolescents with juvenile idiopathic arthritis. Rheumatol Int. 2014;34(11):1483-8. 
13. Maruotti N, Corrado A, Cantatore FP. Osteoporosis and rheumatic diseases. Reumatismo. 2014;66(2):125-35.

14. van der Heijde D, Landewe RB, Mease PJ, McInnes IB, Conaghan PG, Pricop L, et al. Brief report: secukinumab provides significant and sustained inhibition of joint structural damage in a phase III study of active psoriatic arthritis. Arthritis Rheumatol. 2016;68(8):1914-21.

15. Jiang Y, Genant HK, Watt I, Cobby M, Bresnihan B, Aitchison R, et al. A multicenter, double-blind, dose-ranging, randomized, placebo-controlled study of recombinant human interleukin-1 receptor antagonist in patients with rheumatoid arthritis: radiologic progression and correlation of Genant and Larsen scores. Arthritis Rheum. 2000;43(5):1001-9.

16. Bardin T. Canakinumab for the patient with difficult-to-treat gouty arthritis: review of the clinical evidence. Joint Bone Spine. 2015;82(Suppl 1):es9-16.

17. Siebert S, Tsoukas A, Robertson J, McInnes I. Cytokines as therapeutic targets in rheumatoid arthritis and other inflammatory diseases. Pharmacol Rev. 2015;67(2):280-309.

18. Berenbaum F, Griffin TM, Liu-Bryan R. Metabolic regulation of inflammation in osteoarthritis. Arthritis Rheum (Hoboken, NJ). 2017;69(1):9.

19. Farahat MN, Yanni G, Poston R, Panayi GS. Cytokine expression in synovial membranes of patients with rheumatoid arthritis and osteoarthritis. Ann Rheum Dis. 1993;52(12):870-5.

20. Zhao R, Dong Z, Wei X, Gu X, Han P, Wu H, et al. Inflammatory factors are crucial for the pathogenesis of post-traumatic osteoarthritis confirmed by a novel porcine model: "Idealized" anterior cruciate ligament reconstruction" and gait analysis. Int Immunopharmacol. 2021;99:107905.

21. Yoshihara Y, Nakamura H. Obata Ki, Yamada H, Hayakawa T, Fujikawa K, et al. Matrix metalloproteinases and tissue inhibitors of metalloproteinases in synovial fluids from patients with rheumatoid arthritis or osteoarthritis. Ann Rheum Dis. 2000;59(6):455-61.

22. Malfait A-M, Liu R-Q, ljiri K, Komiya S, Tortorella MD. Inhibition of ADAMTS4 and ADAM-TS5 prevents aggrecan degradation in osteoarthritic cartilage. J Biol Chem. 2002;277(25):22201-8.

23. Clements KM, Price JS, Chambers MG, Visco DM, Poole AR, Mason RM. Gene deletion of either interleukin-1 $\beta$, interleukin-1 $\beta$-converting enzyme, inducible nitric oxide synthase, or stromelysin 1 accelerates the development of knee osteoarthritis in mice after surgical transection of the medial collateral ligament and partial medial meniscectomy. Arthritis Rheum. 2003;48(12):3452-63.

24. Nasi S, Ea H-K, So A, Busso N. Revisiting the role of interleukin-1 pathway in osteoarthritis: interleukin-1 $\alpha$ and-1 $\beta$, and NLRP3 inflammasome are not involved in the pathological features of the murine menisectomy model of osteoarthritis. Front Pharmacol. 2017;8:282.

25. Chevalier X, Goupille P, Beaulieu A, Burch F, Bensen W, Conrozier T, et al. Intraarticular injection of anakinra in osteoarthritis of the knee: a multicenter, randomized, double-blind, placebo-controlled study. Arthritis Care Res. 2009;61(3):344-52

26. Kloppenburg M, Peterfy C, Haugen IK, Kroon F, Chen S, Wang L, et al. Phase lla, placebo-controlled, randomised study of lutikizumab, an antiinterleukin-1 $\alpha$ and antiinterleukin-1 $\beta$ dual variable domain immunoglobulin, in patients with erosive hand osteoarthritis. Ann Rheum Dis. 2019;78:413-20

27. Broz P, Dixit VM. Inflammasomes: mechanism of assembly, regulation and signalling. Nat Rev Immunol. 2016;16(7):407-20.

28. Shi J, Zhao Y, Wang K, Shi X, Wang Y, Huang H, et al. Cleavage of GSDMD by inflammatory caspases determines pyroptotic cell death. Nature. 2015;526(7575):660-5.

29. Nyström S, Antoine DJ, Lundbäck P, Lock JG, Nita AF, Högstrand K, et al. TLR activation regulates damage-associated molecular pattern isoforms released during pyroptosis. EMBO J. 2013;32(1):86-99.

30. Xiao J, Wang C, Yao J-C, Alippe Y, Xu C, Kress D, et al. Gasdermin D mediates the pathogenesis of neonatal-onset multisystem inflammatory disease in mice. PLoS Biol. 2018;16(11):e3000047.

31. Kanneganti A, Malireddi RKS, Saavedra PHV, Vande Walle L, Van Gorp $H$, Kambara $H$, et al. GSDMD is critical for autoinflammatory pathology in a mouse model of familial Mediterranean fever. J Exp Med. 2018;215(6):1519-29.

32. Li S, Wu Y, Yang D, Wu C, Ma C, Liu X, et al. Gasdermin D in peripheral myeloid cells drives neuroinflammation in experimental autoimmune encephalomyelitis. J Exp Med. 2019;216(11):2562-81.
33. Kayagaki N, Stowe IB, Lee BL, O'Rourke K, Anderson K, Warming S, et al. Caspase-11 cleaves gasdermin D for non-canonical inflammasome signalling. Nature. 2015;526(7575):666-71.

34. Rashidi M, Simpson DS, Hempel A, Frank D, Petrie E, Vince A, et al. The proptotic cell death effector gasdermin $D$ is activated by gout-associated uric acid crystals but is dispensable for cell death and IL-1 beta release. J Immunol. 2019;203(3):736-48.

35. Ma C, Yang D, Wang B, Wu C, Wu Y, Li S, et al. Gasdermin D in maCrophages restrains colitis by controlling CGAS-mediated inflammation. Sci Adv. 2020;6(21):eaaz6717

36. Bulek K, Zhao J, Liao Y, Rana N, Corridoni D, Antanaviciute A, et al. Epithelial-derived gasdermin D mediates nonlytic IL-1 beta release during experimental colitis. J Clin Invest. 2020;130(8):4218-34.

37. Clohisy JC, Roy BC, Biondo C, Frazier E, Willis D, Teitelbaum SL, et al. Direct inhibition of NF-kappa B blocks bone erosion associated with inflammatory arthritis. J Immunol. 2003;171(10):5547-53.

38. Shen J, Wang C, Ying J, Xu T, McAlinden A, O'Keefe RJ. Inhibition of 4-aminobutyrate aminotransferase protects against injury-induced osteoarthritis in mice. JCI Insight. 2019;4(18):e128568.

39. Glasson S, Chambers M, Van Den Berg W, Little C. The OARSI histopathology initiative-recommendations for histological assessments of osteoarthritis in the mouse. Osteoarthritis Cartilage. 2010;18:S17-23.

40. Jackson MT, Moradi B, Zaki S, Smith MM, McCracken S, Smith SM, et al. Depletion of protease-activated receptor 2 but not proteaseactivated receptor 1 may confer protection against osteoarthritis in mice through extracartilaginous mechanisms. Arthritis Rheumatol. 2014:66(12):3337-48

41. Liu X, Xia S, Zhang Z, Wu H, Lieberman J. Channelling inflammation: gasdermins in physiology and disease. Nat Rev Drug Discov. 2021;20(5):384-405

42. Zhang Y, Lin Z, Chen D, He Y. CY-09 attenuates the progression of osteoarthritis via inhibiting NLRP3 inflammasome-mediated pyroptosis. Biochem Biophys Res Commun. 2021:553:119-25.

43. Yan Z, Qi W, Zhan J, Lin Z, Lin J, Xue X, et al. Activating Nrf2 signalling alleviates osteoarthritis development by inhibiting inflammasome activation. J Cell Mol Med. 2020;24(22):13046-57.

44. Zu Y, Mu Y, Li Q, Zhang ST, Yan HJ. Icariin alleviates osteoarthritis by inhibiting NLRP3-mediated pyroptosis. J Orthop Surg Res. 2019;14(1):307.

45. Ma Z, Huang Z, Zhang L, Li X, Xu B, Xiao Y, et al. Vanillic acid reduces pain-related behavior in knee osteoarthritis rats through the inhibition of NLRP3 inflammasome-related synovitis. Front Pharmacol. 2020;11:599022.

46. Ohashi Y, Uchida K, Fukushima K, Satoh M, Koyama T, Tsuchiya M, et al. Correlation between CD163 expression and resting pain in patients with hip osteoarthritis: possible contribution of CD163+ monocytes/macrophages to pain pathogenesis. J Orthop Res. 2021. https://doi.org/10. 1002/jor.25157. Online ahead of print

47. Kamekura S, Hoshi K, Shimoaka T, Chung U, Chikuda H, Yamada T, et al. Osteoarthritis development in novel experimental mouse models induced by knee joint instability. Osteoarthritis Cartilage. 2005;13(7):632-41.

48. Wang Y, Gao W, Shi X, Ding J, Liu W, He H, et al. Chemotherapy drugs induce pyroptosis through caspase-3 cleavage of a gasdermin. Nature. 2017;547(7661):99-103.

49. Aizawa E, Karasawa T, Watanabe S, Komada T, Kimura H, Kamata R, et al. GSDME-dependent incomplete pyroptosis permits selective IL-1alpha release under caspase-1 inhibition. iScience. 2020;23(5):101070.

50. Wang C, Yang T, Xiao J, Xu C, et al. NLRP3 inflammasome activation triggers gasdermin D-independent inflammation. Sci Immunol. 2021;6:eabj3859.

51. Ippagunta SK, Brand DD, Luo J, Boyd KL, Calabrese C, Stienstra R, et al Inflammasome-independent role of apoptosis-associated speck-like protein containing a CARD (ASC) in T cell priming is critical for collageninduced arthritis. J Biol Chem. 2010;285(16):12454-62.

52. Kolly L, Karababa M, Joosten LA, Narayan S, Salvi R, Petrilli V, et al. Inflammatory role of ASC in antigen-induced arthritis is independent of caspase-1, NALP-3, and IPAF. J Immunol. 2009;183(6):4003-12.

53. Vande Walle L, Van Opdenbosch $N$, Jacques $P$, Fossoul A, Verheugen $E$, Vogel P, et al. Negative regulation of the NLRP3 inflammasome by A20 protects against arthritis. Nature. 2014;512(7512):69-73. 
54. Saijo S, Asano M, Horai R, Yamamoto H, Iwakura Y. Suppression of autoimmune arthritis in interleukin-1-deficient mice in which T cell activation is impaired due to low levels of CD40 ligand and OX40 expression on T cells. Arthritis Rheum. 2002;46(2):533-44.

55. Hu JJ, Liu X, Xia S, Zhang Z, Zhang Y, Zhao J, et al. FDA-approved disulfiram inhibits pyroptosis by blocking gasdermin D pore formation. Nat Immunol. 2020:736-45.

56. Humphries F, Shmuel-Galia L, Ketelut-Carneiro N, Li S, Wang B, et al. Succination inactivates gasdermin D and blocks pyroptosis. Science. 2020;369:1633-7

57. Burr DB. The importance of subchondral bone in osteoarthrosis. Curr Opin Rheumatol. 1998;10(3):256-62.

58. Xiao J, Wang C, Yao J-C, Alippe Y, Yang T, Kress D, et al. Radiation causes tissue damage by dysregulating inflammasome-gasdermin D signaling in both host and transplanted cells. PLoS Biol. 2020;18(8):e3000807.
59. Bondeson J, Blom AB, Wainwright S, Hughes C, Caterson B, Van Den Berg WB. The role of synovial macrophages and macrophage-produced mediators in driving inflammatory and destructive responses in osteoarthritis. Arthritis Rheum Arthritis Care Res. 2010;62(3):647.

60. Sharif H, Wang L, Wang WL, Magupalli VG, Andreeva L, Qiao Q, et al. Structural mechanism for NEK7-licensed activation of NLRP3 inflammasome. Nature. 2019;570(7761):338-43.

61. Weigt SS, Palchevskiy V, Belperio JA. Inflammasomes and IL-1 biology in the pathogenesis of allograft dysfunction. J Clin Invest. 2017;127(6):2022-9.

\section{Publisher's Note}

Springer Nature remains neutral with regard to jurisdictional claims in published maps and institutional affiliations.
Ready to submit your research? Choose BMC and benefit from:

- fast, convenient online submission

- thorough peer review by experienced researchers in your field

- rapid publication on acceptance

- support for research data, including large and complex data types

- gold Open Access which fosters wider collaboration and increased citations

- maximum visibility for your research: over $100 \mathrm{M}$ website views per year

At BMC, research is always in progress.

Learn more biomedcentral.com/submissions 